\title{
From Prototype and Skopos Theories to Corpus-Based and Audiovisual Approaches in Children's Literature Translation
}

\author{
Cristina Chifane \\ The English Department, Faculty of Letters, "Dunărea de Jos” University, Galați, Romania \\ Email: cristinachifane@yahoo.com
}

Received 25 July 2015; accepted 17 August 2015; published 20 August 2015

Copyright (C) 2015 by author and Scientific Research Publishing Inc.

This work is licensed under the Creative Commons Attribution International License (CC BY). http://creativecommons.org/licenses/by/4.0/

(c) (i) Open Access

\begin{abstract}
For a long time an unexploited field of scientific research, Children's Literature Translation Studies deserve a thorough examination primarily due to the current world-wide publishing boom of children's texts. The dominance of the literary productions of the Anglo-American environment determines the overwhelming number of translations in different cultures and languages. Most translation theories which have been traditionally analyzed and applied to what is generally assumed to be adult literature should be revisited and reconsidered in the case of children's books with the aim of helping translators and ensuring the efficiency of the translation process. From this perspective, the present article focuses upon the influence of the prototype theory upon children's literature translation strategies, the importance of the double addressee in the skopos theory, the advantages of the corpus-based approach and the adaptation to the changing landscapes of children's texts intermediated by the audiovisual approach. Since contemporary translators of children's literary texts are facing the imperative of tight deadlines, they need to be clearly aware of their translation commission trying to fulfill the expectations of the potential target readers. The afore-mentioned theories and approaches pave the way to new discoveries with respect to the challenge of translating children's texts which share both similarities and differences with adult literature.
\end{abstract}

\section{Keywords}

Children's Literature, Prototypes, Skopos, Corpus-Based Approach, Audiovisual Approach

\section{Introduction}

According to Lathey, "Recent developments in translation studies offer new methodologies for the analysis of translations for children” [1]. She considers that the theory of prototypical translation, the computer analysis of 
large corpora of translated texts and the reader-response theories highly contribute to the understanding of the translation process of children's literature.

Modern translation theories are characterised by interdisciplinariness and multiple perspectives; hence they are relevant to our present concern. The prototype theory, the skopos theory, the corpus-based translation theory as well as the audiovisual theory reveal some of the most interesting issues related to Children's Literature Translation (CLT).

\section{The Prototype Theory and Its Influence on CLT Strategies}

Developed by Rosch [2], the Theory of Prototypes and Basic-Level Categories relies on the fact that human beings recognise distinctive features in objects and thus combine the objects into certain categories according to different levels of inclusiveness and abstraction. Superordinate is the highest level of inclusiveness and abstraction, basic-level is one level below and subordinate is the lowest level of inclusiveness and abstraction (e.g. animal—dog—retriever).

Following Rosch, Lakoff [3] explains that most of our world knowledge is organised at the basic-level since this is the level at which one uses the shortest description for an object and terms at this level are most commonly used by people. Prototype theory and especially the basic-level acquire a lot of significance in translating literature for children if we look at the definition of the basic-level provided by Shalomi-Hen: "It is the level at which terms are used in neutral context, it is the first level to enter the lexicon, and the first level named and understood by children" [4].

On the other hand, Vîlceanu [5] considers that the semantics of the prototype is in fact a referential mode much more flexible than the classical model of the necessary and sufficient conditions.

The superordinate is one level of abstraction above the basic-level and the categories included here share only a few attributes with each other whereas the subordinate is one level of abstraction below the basic-level and its categories share most of their attributes with each other, many of which overlap with other categories.

Children usually learn new words by including them in one category or another. Picture dictionaries might be organised according to this criterion. To put it differently, the translator of children's texts has to acknowledge the importance of categorisation for children especially when he/she is confronted with situations of non-equivalence when the target language (TL) may lack a term belonging either to the superordinate or to the subordinate levels.

Another interesting aspect about these categories is that most of them, if not all, do not have clear-cut boundaries. In these situations, Thomson-Wohlgemuth underlines the idea that "there is no one to one correspondence from language to language" [6]. In those clear cases given by people as the best example for category membership we can refer to the prototypical members of a community with the amendment that "the more prototypical of a category a member is rated, the more attributes it has in common with other members of the category and fewer attributes in common with members of the contrasting categories" [7].

Understanding the cognitive models of both the source culture (SC) and source language (SL) and that of the target culture (TC) and TL is of vital importance for any translator of children's literature especially since different cultures might have different representatives of a category.

As a consequence, if different cultures have different judgements of degree of prototypicality for different reasons then translating literature for children would mean substituting a particular prototype of the SL with another prototype in the TL. An instance of domestication, this technique will help children form an idea of prototypes in their own culture or at an older age just recognise the prototypes in their culture. On the other hand, translators might choose to preserve the prototypes in the TL if their intention is to introduce the young readers to prototypes in other languages and cultures.

\section{The Double Addressee in the Skopos Theory}

Translating children's literature involves main aims and purposes, therefore the so-called "skopos theory" mentioned by Carta "has proven to be useful in uncovering the mechanisms involved in translating this body of literature" [8]. In translating children's literature, the objectives and functions have a major influence upon the final product:

In the framework of this theory, one of the most important factors determining the purpose of a translation is the addressee, who is the intended receiver or audience of the TT with their culture-specific world know- 
ledge, their expectations and their communicative needs. Every translation is directed at an intended audience, since to translate means to produce a text in a target setting for a target purpose and target addressees in target circumstances. [9]

The relevance of the skopos theory to the study of children's literature in translation is given by the focus on the addressee. The translator has to consider a double addressee (the child and the adult) and consequently choose the educational, pedagogical or entertaining goals he/she thinks are appropriate.

If Children's Literature Translation Studies (CLTS) neglects to specify the commission or the skopos, then there will be no possibility of choosing the best method to translate a given text. The skopos theory expands the possibilities of translation, increases the range of possible translation strategies and releases the translator from the corset of an enforced literalness.

Intentional and unintentional changes affect the entire translation process. Unintentional changes may arise from the different language structures as well as from differences in translating competence. Intentional changes frequently occur in translating, if the aims pursued in the translation are different from those of the original. As far as intentional changes with a negative impact are concerned, CLT has been under the influence of ideology which lead to manipulation and censorship in the countries of the totalitarian regimes.

On the same lines, Shavit [10] and Klingberg [11] agree that there are two main intentions pursued in translating children's literature.

The first consists in trying to adapt the text in order to satisfy the socio-cultural expectations prevailing in the TC, expectations related to what is regarded as pedagogically and morally appropriate and useful for children. The second involves the adaptation to what are believed to be the children's reading and comprehension skills according to their age. These two principles affect the different stages of the translation process and determine the acceptance and the affiliation of a text to the TC. They both coexist and should be integrated in the guideline of a translator of literature for children.

The skopos theory has been criticised and objections mainly concern the definition of translation and the relationship between source text (ST) and target text (TT).

Vermeer himself brings arguments against these objections. In his opinion,

The notion of skopos can in fact be applied in three ways, and thus have three senses: it may refer to

a) the translation process, and hence the goal of this process;

b) the translation result, and hence the function of the translatum;

c) the translation mode, and hence the intention of this mode. [12]

If a given act of behavior has neither goal nor function nor intention, then it is not an action in the technical sense of the word. Another objection would be that not every translation can be assigned a purpose or an intention. On the contrary, the translator of literature for children has specific goals, functions or intentions in mind when he/she translates a text dedicated to children.

In the present theory of translational activity the task of the children's literature translator includes matters of ethics and the translator's accountability. Specific goals, functions and intentions do not restrict the translation possibilities or limit the range of interpretations of the TT in comparison to that of the ST.

In text linguistics and literary theory a distinction is often made between text as potential and text as realisation. When a text for children is actually translated, this is done with respect to an assumed function. The same text might be used later in ways that has not been foreseen originally: "The skopos theory merely states that the translator should be aware that some goal exists and that any given goal is only one among many possible ones" [12]. Consequently, the trajectory of a translated book for children is not always the one expected by the translator or by the publishing houses. After all, success in the SC does not necessarily guarantee success in the TC but it is unquestionably a determining factor.

The claim that the translator has no specific addressee or set of addressees in mind is clearly dismissed in the case of CLT which has to constantly report to the needs and expectations of the child-readers.

The translator of literature for children makes a number of decisions during the translation process. They are primarily based on the skopos, the concrete purpose and aims in a concrete translation commission.

\section{The Advantages of the Corpus-Based Translation Approach}

A corpus-based approach is an asset valuable for both the theoretician and the practitioner in the field. In the development of such a theory, the term corpus is used to mean "any collection of texts held in machine-readable 
form and capable of being analysed automatically or semi-automatically in a variety of ways” [13].

According to structure and organisation, the most frequent type of corpus is the parallel corpus usually made up of SL texts and their translated versions. Two other types could be added. The first is comparable corpora described as either a selection of similar texts in two or several languages or language varieties [14] or as a combination of sub-corpus comprising texts written by native speakers of a language and a second corpus made up of translated texts into the same language as the ones written by natives, the two not being source and target language versions, but independent of each other. The second type is the so-called "learner type" meant to determine the improvement of translator training programmes by investigating the performance of would-be translators based on their examination papers.

Judging by the language or languages involved, corpora are classified into monolingual, bilingual or multilingual ones. A classification by domain or content divides corpora into reference versus specialised ones. Temporality brings about the distinction between synchronic and diachronic corpora. From the viewpoint of the written or spoken modes, corpora can be written, spoken or mixed (written and spoken). In terms of length, the corpus types are: full-text, sample, mixed (full-text and sample) and monitor (made up of full texts which are scanned on an ongoing basis so that the corpus is continually updated). Translating literature for children would require bilingual or multilingual, parallel or comparable corpora. Written full-text, sample or mixed corpora are also necessary. Since a large number of books for children is written and published every year, a monitor corpus type is recommendable in order to provide an update of the latest developments and changes in the field.

Representativeness, size, authorship, time-span and issues of confidentiality and copyright have to be dealt with when opting for any corpus in translation studies (TS). In this respect, CLTS is no exception.

So far, studies in the field of corpus-based translation have indicated that simplification, explicitation, normalisation, repetition avoidance, leveling out, disambiguation and standardisation are some of the tendencies of translation products. The research team is supposed to report both quantitative and qualitative results.

The tools for quantitative research are borrowed from corpus linguistics and include word frequency lists, text concordances and statistics [14]. In addition, originals as well as translations are analysed contrastively at both the textual and the linguistic levels in terms of discourse (cohesion and coherence), morpho-syntactic structure, lexis (frequency and density, distribution, contextualisation), stylistic and semantic features or register.

The advantages of corpus-based translation are numerous: lexical search and documentation cease to be so time-consuming and counterproductive; if the data are reliable, then immediate accessibility is a point in favour of a good translation; the richer the corpus, the higher the chances to translate better finding the word, collocation, phrase or idiomatic expression that fits the context.

Using the corpus-based analysis method, researchers could highlight differences between literary translations for children and for adults. For example, the degree of explicitation varies in books for children in comparison with books for adults.

A corpus-based research regarding noun density, added connectives and added notes would most probably prove that CLT displays a higher degree of explicitation than adult literature translation. In fact, a variety of translation variables of CLT versus adult literature translation would be understood and explained if corpus-based translations were given priority. Last but not least, universals of CLT (features which are hypothesised to be common to all translated texts regardless of text type and language pair) could be identified.

\section{The Audiovisual Approach or Changing Landscapes in CLT}

First of all, translating literature for children in the wider context of globalisation means being aware of the multiple and different modes of translating in contemporary society. The audio (radio), the audio and the visual (screen), or the written, the audio and the visual (multimedia) channels could represent the ST. In all these situations, audiovisual translation is called "to encompass all translations_-or multisemiotic transfer-for production or postproduction in any media or format, and also the new areas of media accessibility: subtitling for the deaf and the hard-of-hearing and audiodescription for the blind and the visually impaired" [15].

At present, the quantity of output is huge so audiovisual translation is indeed one of the fastest growing areas in the field of TS. Training in audiovisual translation, particularly subtitling and dubbing has gradually become part of the curricula of some major Romanian universities.

Diaz Cintas [16] has also noticed a general surge in interest: the Schools of Translation and Interpreting have proliferated enormously in recent years and compulsory or optional modules on audiovisual translation are 
common on university undergraduate programmes as well as on a number of postgraduate programmes, notably at master degree level.

Since younger children are unlikely to be able to read subtitles "screen translation for this age group is therefore dominated by dubbing” [1]. As an illustration, O’Connell's [17] study of the dubbing of a German-language animated children's television series into Irish identifies both lexical simplification and the reduction of dual address, thus replicating findings in studies of written texts. On the other hand, screen adaptations for older children and teenagers allow for subtitling which should be the work of a professional translator.

In addition to the obvious difference in price (subtitling is cheaper than dubbing), there are other elements that distinguish the two forms of screen translation. O’Connell [18] elaborates upon the dubbing process. When a film or video is to be dubbed, a script translator usually provides a complete draft translation which serves as a basis for the final, usually somewhat adapted, version that emerges when dubbing actors, producers and directors get together in the dubbing studio. The dubbing script translator usually faces many of the same linguistic challenges as those associated with the drafting of foreign language versions of other oral material, for example radio and theatre plays. The task is typically complicated by the constraints imposed by the need to achieve good quality lip synchrony whenever as possible, syllable count and sentence length in the source and target versions.

For instance, while there is over-representation of SL features in film subtitling, TL-specific features are more commonly found in dubbing scripts. One of the difficulties in dubbing is the inability to express foreign accents and local dialects. Nevertheless, both forms of screen translation should be employed taking into account the age and comprehension-abilities of the children in the TC.

Children and young adults also form a significant audience for translated video games. Mentioning Bernal-Merino's investigation of video game software based on children's books, Lathey [1] contends that this investigation proves that the localisation of such texts requires considerable technical acumen, since localisers have to translate multiple formats including operating instructions, coded text and periodic game updates.

Professional training in the field is mandatory: "Translating games for child viewers demands that such expertise be combined with an understanding of the child audience and the role of text and image in games designed for children" [1].

Some might argue that audiovisual translation and literary translation have nothing in common. From our perspective, the former was generated by the latter and audio and screen productions for children are in fact ramifications of the written texts. Moreover, they have emerged as an answer to changing landscapes dominated by new media and technologies. For example, Rowling's Harry Potter book series has given birth to an entire entertainment industry, audio books, film series and video games included.

If we expand the notion of children's literature to a very broad field encompassing everything that a child reads or hears, "plays, puppet shows, computer and video games, radio and TV programmes, films, videos etc. are just as important as books in terms of the education and entertainment of young people” [18]. In the case of such texts, it is more appropriate to speak of listeners or viewers rather than readers, therefore Oittinen [19] suggests that the more general term of receptor should now be used.

Last but not least, the impact of new computer technology changes our conceptualisation of translation in general and of CLT in particular. For Littau [20], the environment and format of the hypertext influences the way in which people write, read and translate.

Hypertext allows people to arrange and rearrange text, to disperse fragments of text, insert them into other texts, connect, dis- and interconnect texts as well as images. Computer technology can display texts in a variety of formats and layouts to the benefit of translators for children who have to profit from the possibility of using this technology since it is well-known that children are attracted to sound and image.

To sum up, the current discourse of the translator's visibility is nowhere better realised than in the hypertext environment which locates visibility in the text rather than outside the text (in prefaces, footnotes and critical commentaries).

\section{Conclusions}

Although reaching full development in the 1970s and 1980s, the prototype theory could be used to explain the choice of translation strategies in the case of children's literature. Whenever translators have to deal with nonequivalence because of a lack of a term belonging either to the superordinate or to the subordinate levels, they become aware of the role of a categorization especially in the case of a cultural transfer which will most defi- 
nitely affect the children's perception of a text.

What is more, children and adolescents in contemporary society differ from the same audience a century ago; many of the historical taboos embedded in either the writing or the translation process of children's literary texts no longer hold valid in present times. As a consequence, the skopos theory is meant to identify the translation commission and to facilitate the employment of either domestication or foreignization in accordance with the educational or entertaining goals expected to reach a wider target readership.

On the same wavelength, the corpus-based approach is an invaluable asset for both the theoretician and the practitioner in the field of CLTS since its differences between children's and adult literature and at the same time a large corpus increases the chances of finding the appropriate equivalent in the TL.

Last but not least, translators need to adapt their strategies to the multiple and different modes of translating in contemporary society. Under the circumstances, the audiovisual approach brings CLTS into the $21^{\text {st }}$ century transforming the child reader into a listener and viewer, an inquisitive receptor of extremely versatile texts.

\section{Fund}

This paper was supported by Project SOP HRD—PERFORM/159/1.5/S/138963.

\section{References}

[1] Lathey, G. (2011) The Translation of Literature for Children. In: Malmkjaer, K. and Windle, K., Eds., The Oxford Handbook of Translation Studies, Oxford University Press, Oxford, 198-214. http://dx.doi.org/10.1093/oxfordhb/9780199239306.013.0015

[2] Rosch, E. (1978) Principles of Categorisation. In: Rosch, E. and Lloyd, B.B., Eds., Cognition and Categorisation, Lawrence Erlbaum, Hillsdale, 27-48.

[3] Lakoff, G. (1987) Women, Fire and Dangerous Things: What Categories Reveal about the Mind. University of Chicago, Chicago. http://dx.doi.org/10.7208/chicago/9780226471013.001.0001

[4] Shalomi-Hen, R. (2000) Classifying the Divine. Hubert \& Co, Göttingen.

[5] Vîlceanu, T. (2007) Fidelitate şi alteritate lingvistică şi culturală. Editura Universitaria, Craiova.

[6] Thomson-Wohlgemuth, G. (1998) Children's Literature and Its Translation. An Overview. Unpublished. MA Dissertation, University of Surrey, Surrey.

[7] Rosch, E. and Marvis, C.B. (1975) Family Resemblance: Studies in the Internal Structure of Categories. Cognitive Psychology, 7, 573-605. http://dx.doi.org/10.1016/0010-0285(75)90024-9

[8] Carta, G. (2008) Theory and Practice of Translation: The Case of Children's Literature. In: Hyde Parker, R. and Guadarrama Garcia, K., Eds., Thinking Translation: Perspectives from Within and Without, Brown Walker Press, Boca Raton, 35-47.

[9] Nord, C. (1991) Skopos, Loyalty and Translation Conventions. Target, 3, 91-109. http://dx.doi.org/10.1075/target.3.1.06nor

[10] Shavit, Z. (1986) Translation of Children's Literature. The University of Georgia Press, London.

[11] Gote, K., Orvig, M. and Stuart, A. (1978) Children’s Books in Translation: The Situation and the Problems. Almqvist \& Wiksell International, Stockholm.

[12] Venuti, L. (1995) The Translator’s Invisibility. A History of Translation. Routledge, London. http://dx.doi.org/10.4324/9780203360064

[13] Baker, M. (1995) Corpora in Translation Studies: An Overview and Suggestions for Future Research. Target, 7, 223242. http://dx.doi.org/10.1075/target.7.2.03bak

[14] Laviosa-Braithwaite, S. (2002) Corpus-Based Translation Studies. Rodopi, Amsterdam/New York.

[15] Orero, P. (2004) Topics in Audiovisual Translation. John Benjamins, Amsterdam/Philadelphia. http://dx.doi.org/10.1075/btl.56

[16] Diaz-Cintas, J. (2008) The Didactics of Audiovisual Translation. John Benjamins, Amsterdam/Philadelphia. http://dx.doi.org/10.1075/btl.77

[17] O’Connell, E. (2003) Minority Language Dubbing for Children: Screen Translation from German to Irish. Peter Lang, Bern.

[18] O’Connel, E. (1999) Translating for Children. In: Anderman, G. and Rogers, M., Eds., Word, Text, Translation: Liber Amicorum for Peter Newmark, Multilingual Matters, New York, 208-216. 
[19] Oittinen, R. (1993) I Am Me-I Am Other: On the Dialogics of Translating for Children. University of Tampere, Tampere.

[20] Littau, K. (2010) Translation in the Age of Postmodern Production: From Text to Intertext to Hypertext. In: Baker, M., Ed., Creatical Readings in Translation Studies, Routledge, New York, 435-448. 